\title{
Abdominal Fat Reduction through Cryolipolysis
}

\author{
Doyeop Lee, Kyurae Lee* \\ Gachon University, Seongnam, Korea \\ Email: ^baria07@daum.net
}

How to cite this paper: Lee, D. and Lee, K. (2018) Abdominal Fat Reduction through Cryolipolysis. Journal of Biosciences and Medicines, 6, 44-52. https://doi.org/10.4236/jbm.2018.69005

Received: August 9, 2018

Accepted: September 14, 2018

Published: September 17, 2018

Copyright ( 92018 by authors and Scientific Research Publishing Inc. This work is licensed under the Creative Commons Attribution International License (CC BY 4.0).

http://creativecommons.org/licenses/by/4.0/ (c) (i) Open Access

\begin{abstract}
Although several studies showed the efficacy and safety from this procedure, the comparative assessment of adipose tissue by cryolipolysis has not been studied until now. Therefore we investigated the quantitative change of cross sectional areas of abdominal SAT (subcutaneous adipose tissue) and VAT (visceral adipose tissue) following cryolipolysis. A prospective study for twelve subjects with a single session of cryolipolysis on abdomen was performed. We assessed for their height, weight, and waist circumferences, body contours by photographs, and the cross sectional areas of visceral and subcutaneous adipose tissues were measured at umbilicus level by computerized tomography for 2 months. The cross sectional areas in SAT reduced from $243.3 \pm 24.7$ to $238.5 \pm 40.7 \mathrm{~cm}^{2}$ at 2 months post-treatment. Those of VAT reduced from $141.3 \pm 46.4$ to $125.1 \pm 42.8 \mathrm{~cm}^{2}$ at 2 months post-treatment. Cross sectional areas of VAT, and waist circumferences were significantly reduced by $16.2 \mathrm{~cm}^{2}, 4.1 \mathrm{~cm}$ respectively. Additionally visual improvement without unexpected adverse events was noted. In conclusion a single session cryolipolysis demonstrated to reduce visceral adipose tissue as well as waist circumferences tissue for 2 months. Further controlled study would be needed to evaluate for reduction of visceral adipose tissue by cryolipolysis.
\end{abstract}

\section{Keywords}

Visceral Adipose Tissue, Subcutaneous Adipose Tissue, Cryolipolysis, Body Contour, Weight

\section{Introduction}

Whereas previous study considers visceral adipose tissue as the major culprit to cardio-metabolic mortalities, surgical fat reduction can handle subcutaneous adipose tissue only [1].

Conventional fat removal is achieved by surgical approaches such as liposuc-

${ }^{*}$ Corresponding author: Kyu Rae Lee MD, Ph.D. Family Medicine. Dong Incheon Gil Hospital, Gachon University, 22318, Incheon, Korea. T: 8232-770-1221, Fax: 8232-764-9022. 
tion or lipectomy, however, which are invasive methods with risks of infection, hemorrhage, scarring [2]. Additionally it has some limitation such as expensiveness, and longer postop care, postop mortalities, even without metabolic improvement [3].

Cryolipolysis may be considered as one of replaceable applications to surgical fat reduction approaches for noninvasiveness and selective reduction of subcutaneous adipose tissue without injuries of surrounding tissues since US Food and Drug Administration approved it in 2010 [4] [5].

The most likely mechanism hypothesized when popsicle panniculitis was first described is that crystallization of cytoplasmic lipids in adipocytes occurs at temperatures well above the freezing point of tissue water. In addition, lipid crystals progress to a natural inflammation process, which causes apoptosis [6] [7] [8].

Since introduction of the potential for tissue-specific cold injury, grossly obvious loss of several millimeters of subcutaneous fat showed at 3.5 months of follow-up in a Black Yucatan pig model. Inflammation and adipose tissue loss proceeded for 2 weeks after a single, local exposure to cold, reaching an apparent maximum at 4 weeks after and resolving about 12 weeks after cold exposure through the experiment. In its early inflammatory phase, panniculitis may further damage adipocytes. In its later phase, however, phagocytosis appears to account for removal of adipocytes and loss of fat tissue [9] [10].

The detailed biological mechanisms about selective cryolipolysis remain to be investigated. Most importantly, there is not enough information available in the published literature regarding the mechanisms of adipocyte injury in adult humans when subzero temperatures are applied to the surface of skin. In addition, selective cryolipolysis might be challenging by the fact that human fat is rich in unsaturated fatty acids with a much lower freezing point as opposed to pig fat, which is rich in saturated fatty acids with a rather higher melting point. Recently, however, human clinical studies showed effectiveness of cryolipolysis. Additionally safety of cryolipolysis demonstrated in some studies on the content of serum lipid levels, liver function tests and peripheral nerve injury [10] [11]. In addition we compared laboratory findings following cryolipolysis on gluteal fat for 12 weeks' study in Korean women [12].

Korea FDA (Food and Drug Administration) approved the machine named Cryo-Elsa (Huons, Korea) in 2016. Therefore, we tried to evaluate the clinical efficacy and safety of Cryo-Elsa to remove the abdominal fat tissues especially visceral and subcutaneous adipose tissues on apparently healthy Koreans for 8 weeks.

\section{Methods}

\subsection{Subjects}

As an open clinical intervention trial, intuitional review board reviewed the protocol (DGIL-20161130-01-01) which understood by thirteen participants. 
Potential side effects was been written on the informed consent forms given to all thirteen subjects. Thirteen recruited subjects were $40.8 \pm 8.3$ years $(53.8 \% ; 7$ women), $27.8 \pm 2.6 \mathrm{~kg} / \mathrm{m}^{2}$.

Included were apparently healthy men or women with visible fat on the abdomen with $\mathrm{BMI} \geq 22$ and those without change over $5 \%$ of the former weight within the past 6 months.

Excluded were those who if they had a known history of cryoglobulinemia, cold urticaria, impaired peripheral circulation, Raynauds disease or paroxysmal cold hemogobulinemia. Individuals who had metabolic derangement such as Type 2 DM, dyslipidemia or any medications to regulate weight or fat mass over 6 months were ineligible. In addition, excluded were pregnant or lactating women within 6 months or next 3 months.

Power analysis for a Wilcoxon signed-rank test conducted to determine a sufficient sample size using an alpha of 0.05 , a power of 0.80 , and one tail [13]. Based on the aforementioned assumptions, the desired sample size is 12 .

\subsection{Devices}

Cryo-Elsa is a kind of cryolipolysis machine approved by Korea Food Drug Agency in 2016. It consists of main body (control unit; $473 \times 756 \times 1200 \mathrm{~mm}$ ), gel pad, two vacuum applicators and its liner to keep dermal area at low temperature $\left(-3^{\circ} \mathrm{C}\right.$ to $\left.-9^{\circ} \mathrm{C}\right)$, and provides massage after balancing condition between cooling and vacuum status on target area. Controlled cooling applied through the skin to the fat layer using by new cryolipolysis device (Cryo-Elsa, Huons, Korea). The applicator head using mild vacuum positions the tissue between two cooling panels within the cup and holds it in place for 60-min exposure of the procedure. Cooling maintained for a predetermined period to damage the fat cells.

\subsection{Anthropometric and Body Contour Assessment}

We measured the height and weight of thirteen subjects by digital portable standiometer (DS-102, JENIX, Korea), and assessed their waist circumferences at anterior superior iliac spine level with scales [14]. All subjects instructed to keep their ordinary behavioral attitude such as diet and physical activity. In addition, we assessed their body contours including frontal, both lateral and back views by photography with camera (Samsung SM-N920S, Korea) at initial and 8th week visit by the trained nurse.

\subsection{Treatment}

Precisely controlled cooling applied to the both frontal abdomen areas including love handle with two applicators at the umbilicus level, by same operator on single session treatment. The total treatment time per application site was $60 \mathrm{~min}$ at $-7^{\circ} \mathrm{C}$.

\subsection{Efficacy Assessment and Blood Chemistry}

We performed abdominal fat computerized tomography to assess the efficacy of 
the cryolipolysis procedure after fasting for 8 hours at initial and 8th week. We compared the cross sectional areas of VAT (Visceral Adipose Tissue) and SAT (Subcutaneous Adipose Tissue) in $\mathrm{cm}^{2}$ using by abdominal computerized tomography (Spuria, Hitachi, Japan, 2016) at umbilicus level, and obtained FPG (Fasting plasma glucose), total cholesterol, and HDL-cholesterol, TG (Triglyceride), and Aspartate Transaminase (AST), Alanine Transaminase (ALT) after fasting for 8 hours at initial and 8th week.

\subsection{Statistics}

The sample size was small for parametric analysis, and a Wilcox signed rank test performed for statistics using by SPSS program (version 18), and the probability less than 0.05 was considered as significant at two side level.

\subsection{Monitoring for Safety}

The low temperatures may have deleterious effects on the vascular cells in the adipose tissue, which may cause complications during adipose tissue recovery. We monitored if subjects complained adverse event such as cold burn, pain, and any dermatologic problem including paroxysmal adipocyte hyperplasia following Cryo-Elsa treatment [15].

\section{Results}

We excluded one subject (case 7) who gained her weight (68 to $72 \mathrm{~kg} ; 5.9 \%$ gain) over $5 \%$ for 2 months. We assessed twelve subjects ( $41.7 \pm 8.0$ years, 27.9 $\pm 2.7 \mathrm{~kg} / \mathrm{m}^{2}, 6$ women; $50 \%$ ) as completers.

\subsection{Cross Sectional Areas of Subcutaneous, Visceral Adipose Tissues, and Weight, BMI}

The demographic variables, waist circumferences and the cross sectional areas of adipose tissue described at baseline and 8th week. Their waist circumferences significantly decreased by $4.1 \pm 6.3 \mathrm{~cm}(\mathrm{P}=0.023)$, however both of weight and BMI increased by $0.1 \pm 1.2 \mathrm{~kg}(\mathrm{P}=0.777), 1.9 \pm 0.6 \mathrm{~kg} / \mathrm{m}^{2}(\mathrm{P}=0.528)$ (Table 1$)$.

While the cross sectional areas of SAT decreased by $4.8 \pm 24.9 \mathrm{~cm}^{2}(\mathrm{P}=$ $0.182)$, was the significant decrease noted in that of VAT by $16.2 \pm 20.1 \mathrm{~cm}^{2}(\mathrm{P}=$ 0.023). Their changes of cross sectional areas of fat tissue (SAT, VAT) of illustrated case can be seen (Figure 1).

\subsection{Appraisal for Body Contour}

We took pictures twelve subjects with frontal, both lateral, and back view to compare body surface contour after single treatment. We found visual improvement for body contour in several cases (Figure 2).

\subsection{Biochemical Parameters and Adverse Events}

The changes in FPG, total cholesterol, TG, HDL-cholesterol were $-5.5 \mathrm{mg} / \mathrm{dL}$ 
Table 1. Comparison of demographic, anthropometric and biochemical parameters.

\begin{tabular}{|c|c|c|c|}
\hline \multirow{2}{*}{ Variables } & Baseline & $\begin{array}{c}8 \text { week } \\
\text { after treatment }\end{array}$ & \multirow[t]{2}{*}{$\mathrm{P}$} \\
\hline & \multicolumn{2}{|c|}{ Mean (Standard Deviation) } & \\
\hline Age (years) & & & \\
\hline \multirow{2}{*}{$\operatorname{Sex}(N=12)$} & Male & Female & \\
\hline & $\mathrm{N}=6$ & $\mathrm{~N}=6$ & \\
\hline Weight $(\mathrm{kg})$ & $77.3(15.4)$ & $77.4(15.2)$ & 0.777 \\
\hline BMI $\left(\mathrm{kg} / \mathrm{m}^{2}\right)$ & $27.9(2.7)$ & $28.1(2.8)$ & 0.528 \\
\hline Cross Sectional Areas of VAT $\left(\mathrm{cm}^{2}\right)$ & $141.3(46.4)$ & $125.1(42.8)$ & 0.023 \\
\hline Cross Sectional Areas of SAT $\left(\mathrm{cm}^{2}\right)$ & $243.3(24.7)$ & $238.5(40.7)$ & 0.182 \\
\hline Waist Circumference $(\mathrm{cm})$ & $97.4(7.2)$ & $93.3(7.3)$ & 0.023 \\
\hline Fasting Plasma Glucose (mg/dL) & $106.2(25.4)$ & $100.7(8.3)$ & 0.326 \\
\hline Total Cholesterol (mg/dL) & $210.3(38.1)$ & $188.9(28.2)$ & 0.060 \\
\hline Triglyceride (mg/dL) & $160.6(93.0)$ & $106.7(59.6)$ & 0.034 \\
\hline HDL-Cholesterol (mg/dL) & $59.4(18.5)$ & $57.7(17.9)$ & 0.142 \\
\hline $\begin{array}{c}\text { AST (Aspartate Transaminase) } \\
(\mathrm{IU} / \mu \mathrm{L})\end{array}$ & $31.0(11.0)$ & $29.6(12.5)$ & 0.755 \\
\hline $\begin{array}{c}\text { ALT (Alanine Transaminase) } \\
(\mathrm{IU} / \mu \mathrm{L})\end{array}$ & $35.7(20.7)$ & $38.8(36.8)$ & 0.969 \\
\hline
\end{tabular}

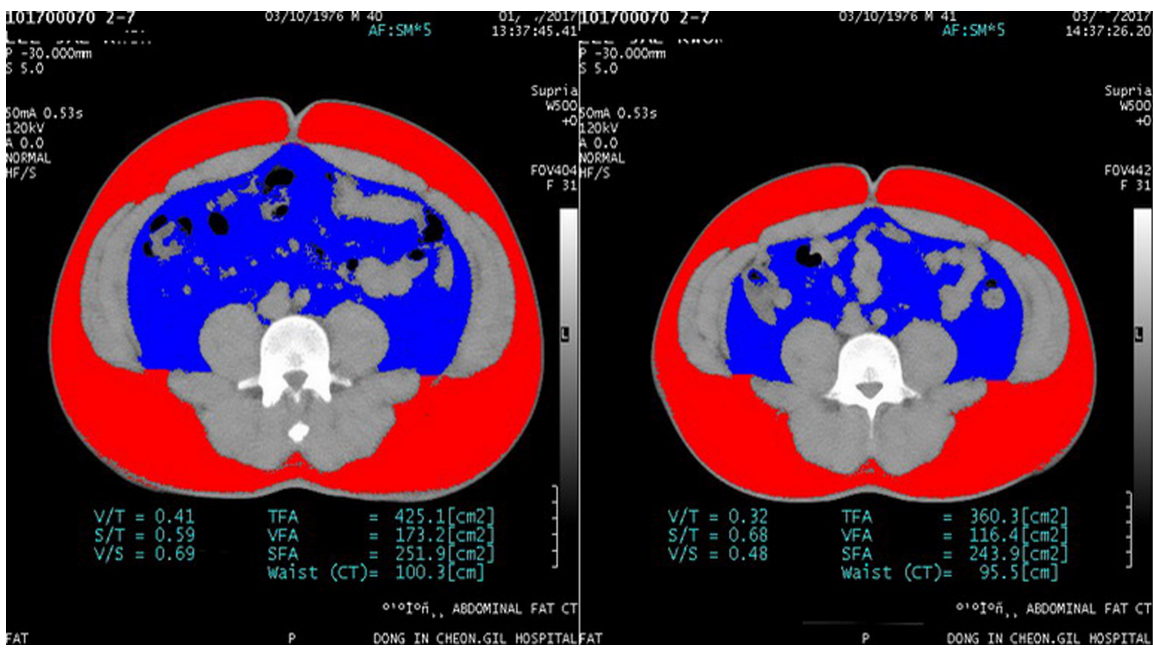

Figure 1. Cross-sectional areas in adipose tissues by CT.

$(\mathrm{P}=0.326),-21.4 \mathrm{mg} / \mathrm{dL}(\mathrm{P}=0.06),-53.9 \mathrm{mg} / \mathrm{dL}(\mathrm{P}=0.03),-1.7 \mathrm{mg} / \mathrm{dL}(\mathrm{P}=$ 0.142 ), respectively. In addition, observed changes of AST and ALT were by $-1.4 \mathrm{IU} / \mu \mathrm{L}, 3.1 \mathrm{IU} / \mu \mathrm{L}$ respectively without statistical significance (Table 1 ).

Several subjects reported transient pain, numbness, erythema and bruising at the treatment area in a week. All of the side effects were mild and resolved without any intervention within 4 or 6 weeks.

\section{Discussion}

Previous studies considered cryolipolysis as a useful method to reduce subcutaneous fat in unwanted area such as flank, abdomen. We found that mean reduction 


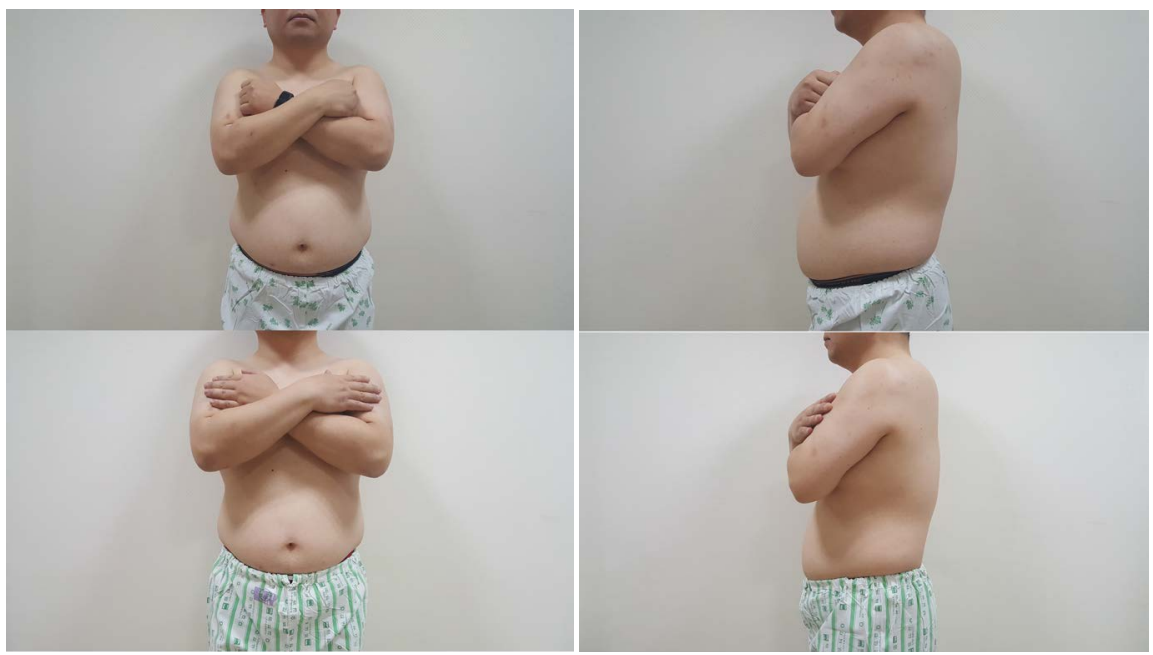

Figure 2. Visual assessment by photography for body contours (Frontal \& Left Lateral View).

of $4.8 \mathrm{~cm}^{2}$ in the abdominal subcutaneous fat by measured cross sectional areas of subcutaneous adipose tissue through computerized tomography at umbilicus level.

As already known in other studies, inflammation and adipose tissue loss processes were reaching an apparent maximum around 4 weeks after cold exposure, resolving about 12 weeks after. In the later phase, phagocytosis appeared to be accounted for the removal of adipocytes and loss of fat tissue [9]. We assessed at 8 weeks, while others reassessed at 3 or 6 months. Better result might-be shown for fat reduction with longer follow-up, for example 3 or 6 months.

Until now, previous researchers used by devices such as ultrasound device, $2 \mathrm{D}$ or $3 \mathrm{D}$ photograph imaging and caliper in order to demonstrate reduction in fat thickness. CT scans are accurate and have the advantage of measuring certain body fat compartments, such as subcutaneous fat [16]. Therefore we confirmed that subcutaneous adiposetissues decreased after the procedure.

At the same time, it is first demonstrated study to identify changes in visceral fat through CT scans. Although several studies shown for fat reduction, no human study has demonstrated the decrease of visceral adipose tissue following a single session cryolipolysis. There is the question of why does the visceral fat decrease, although the depth of treatment was not enough to visceral fat area.

In this study, we found that waist circumference and adipose tissue clinically decreased, but we could not investigate the histological change of actual adipose tissue as showed in other study [17]. Therefore, experimental study with histological approaches would be challenging to confirm the performance of cryolipolysis in the future.

Previous Korean study found no significant changes in lipid level or liver function test over the 8-week or 12-week follow-up period [12]. Liver function levels were mildly changed after the treatment, which remained within normal limits and were similar to those of previous studies [18] [19]. No significant 
changes in liver function and lipid level suggested that fat released through Cryo-Elsa, was cleared by the natural metabolic pathways and it was a safe technique comparable to other cryolipolysis devices.

Some subjects experienced transient pain, numbness, erythema and bruising at the treatment area. All side effects, including numbness, were temporary and resolved without any intervention. Thus, there is no permanent damage to nerve function similar to the study by Coleman et al. [10].

We instructed thirteen subjects to keep their ordinary life style for treatment period. Because we did not monitor the energy intake and expenditure, and adjust age and sex without control, as well as exclusion of one weight gainer over $5 \%$ of initial weight, the present study may have the biased conclusion (Table 2). In addition, it is not enough to demonstrate the effectiveness of fat reduction through cryolipolysis using by twelve recruited subjects. Although the above described limitations, the cross sectional areas of visceral adipose tissue and waist circumferences of completers group significantly decreased despite gaining of weight $(0.1 \pm 1.2 \mathrm{~kg})$ following single session treatment (Figure 3$)$.

We could not find any clear biological plausible mechanism why the cross sectional areas of visceral adipose tissue decreased. However, we suggest that cooling method might induce apoptosis in visceral fat beyond peritoneum depending upon the depth of thermal probe according to recent experimental study [20]. Visceral fat associated hormone such as vaspin, adipokine with

Table 2. Descriptive data of Weight, WC, VAT, SAT parameters.

\begin{tabular}{ccccc}
\hline & Minimum & Maximum & Mean & S.D \\
\hline Height $(\mathrm{cm})$ & 149 & 180 & 165.33 & 11.26 \\
Initial Weight $(\mathrm{kg})$ & 57 & 103 & 77.26 & 15.49 \\
Final Weight $(\mathrm{kg})$ & 56 & 104 & 77.38 & 15.24 \\
Initial BMI $\left(\mathrm{kg} / \mathrm{m}^{2}\right)$ & 22.27 & 31.79 & 27.99 & 2.65 \\
Final BMI $\left(\mathrm{kg} / \mathrm{m}^{2}\right)$ & 21.87 & 32.10 & 28.10 & 2.81 \\
Initial WC $(\mathrm{cm})$ & 86 & 106.5 & 97.38 & 7.20 \\
Final WC $(\mathrm{cm})$ & 83 & 106 & 93.25 & 7.30 \\
\hline
\end{tabular}

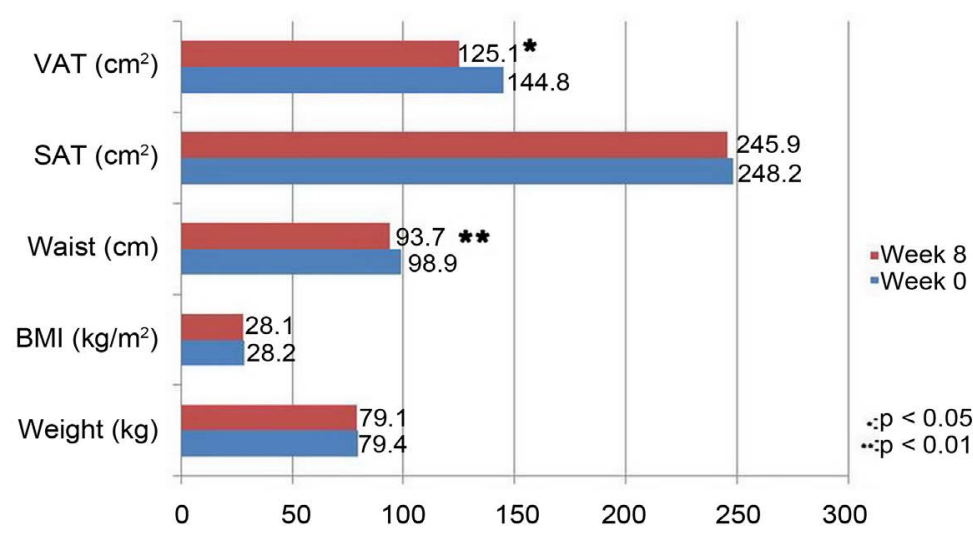

Figure 3. Comparison of Weight, WC, VAT, SAT parameters for 8 weeks. 
cryolipolysis would be included in the future. Larger and controlled study would be demanding, in order to recover its limitation and stronger statistical strength in the future.

Cryolipolysis is still relatively new technology that requires further research. A subsequent treatment leads to further reduction in fat thickness. Not only the first treatment but also the second treatment showed a statistically was statistically significant decrease in the abdomen [21]. However, additional studies are needed for the interval and frequency of repetitive procedures. Alternative cooling and heating as a more effective new protocolis appropriate for the precise and effective destruction [22]. Based on these results, it is necessary to develop a more effective treatment method suitable for each individual. Although pathophysiology of cryolipolysis remains to be studied and more effective treatment protocol should be developed, non-invasive cryolipolysis is still an attractive technology. Cryolipolysis (Cryo-Elsa) is a safe and effective procedure for adipose tissue reduction with minor adverse effects.

Cryolipolysis using by Cryo-Elsa (Huons) showed to reduce abdominal visceral adipose tissue on abdomen in apparently healthy Koreans for 8 weeks. In conclusion, cryolipolysis using by Cryo-Elsa (Huons) on apparently healthy Korean is a safe and effective method to reduce abdominal fat in Korean.

\section{Acknowledgements}

Partially funded by Huons Company, Korea. We thank our colleagues who provided insight and expertise that greatly assisted the research.

\section{Conflicts of Interest}

Device (Cryo-Elsa) provided by Huons Company (Korea).

\section{References}

[1] Berry, M.G. and Davies, D. (2010) Liposuction: A Review of Principles and Techniques. Journal of Plastic, Reconstructive \& Aesthetic Surgery, 64, 985-992. https://doi.org/10.1016/j.bjps.2010.11.018

[2] Bellini, E., Grieco, M.P. and Raposio, E. (2017) A Journey through Liposuction and Liposculture: Review. Annals of Medicine and Surgery, 24, 53-60. https://doi.org/10.1016/j.amsu.2017.10.024

[3] Klein, S., Fontana, L., Young, V.L., et al. (2004) Absence of an Effect of Liposuction on Insulin Action and Risk Factors for Coronary Heart Disease. The New England Journal of Medicine, 350, 2549-2557.

[4] Avram, M.M. and Harry, R.S. (2009) Cryolipolysis ${ }^{\mathrm{TM}}$ for Subcutaneous Fat Layer Reduction. Lasers in Surgery and Medicine, 41, 703-708. https://doi.org/10.1002/1sm.20864

[5] Stewart, K.J., Stewart, D.A., Coghlan, B., Harrison, D.H., Jones, B.M. and Waterhouse, N. (2006) Complications of 278 Consecutive Abdominoplasties. Journal of Plastic, Reconstructive \& Aesthetic Surgery, 59, 1152-1155. https://doi.org/10.1016/j.bjps.2005.12.060

[6] Epstein Jr., E.H. and Oren, M.E. (1970) Popsicle Panniculitis. The New England 
Journal of Medicine, 282, 966-967. https://doi.org/10.1056/NEJM197004232821709

[7] Karow Jr., A.M. and Webb, W.R. (1965) Tissue Freezing. A Theory for Injury and Survival. Cryobiology, 2, 99-108. https://doi.org/10.1016/S0011-2240(65)80094-3

[8] Beacham, B.E., Cooper, P.H., Buchanan, C.S. and Weary, P.E. (1980) Equestrian Cold Panniculitis in Women. Archives of Dermatology, 116, 1025-1027. https://doi.org/10.1001/archderm.1980.01640330063014

[9] Manstein, D., Laubach, H., Watanabe, K., Farinelli, W., Zurakowski, D. and Anderson, R.R. (2008) Selective Cryolipolysis: A Novel Method of Non-Invasive Fat Removal. Lasers in Surgery and Medicine, 40, 595-604. https://doi.org/10.1002/lsm.20719

[10] Coleman, S.R., Sachdeva, K., Egbert, B.M., Preciado, J. and Allison, J. (2009) Clinical Efficacy of Noninvasive Cryolipolysis and Its Effects on Peripheral Nerves. Aesthetic Plastic Surgery, 33, 482-488. https://doi.org/10.1007/s00266-008-9286-8

[11] Zelickson, B., Egbert, B.M., Preciado, J., Allison, J., Springer, K., Rhoades, R.W. and Manstein, D. (2009) Cryolipolysis for Noninvasive Fat Cell Destruction: Initial Results from a Pig Model. Dermatologic Surgery, 35, 1462-1470. https://doi.org/10.1111/j.1524-4725.2009.01259.x

[12] Lee, K.R. (2013) Clinical Efficacy of Fat Reduction on the Thigh of Korean Women through Cryolipolysis. Journal of Obesity \& Weight Loss Therapy, 3, 1-5.

[13] Faul, F., Erdfelder, E., Buchner, A. and Lang, A.-G. (2013) GPower Version 3.1.7 (Computer Software). Universität Kiel, Kiel.

[14] http://www.statcan.gc.ca/pub/82-003-x/2012003/article/11707/c-g/fig1-eng.htm

[15] Jalian, H., Avram, M.M., Garibyan, L., Mihm, M.C. and Anderson, R. (2014) Paradoxical Adipose Hyperplasia after Cryolipolysis. JAMA Dermatology, 150, 317-319. https://doi.org/10.1001/jamadermatol.2013.8071

[16] Hu, F. (2008) Measurements of Adiposity and Body Composition. In: Hu, F.B., Ed., Obesity Epidemiology, Oxford University Press, New York, 53-83.

https://doi.org/10.1093/acprof:oso/9780195312911.003.0005

[17] Meyer, P.F., da Silva, R.M., Oliveira, G., Tavares, M.A., Medeiros, M.L., Andrada, C.P. and Neto, L.G. (2016) Effects of Cryolipolysis on Abdominal Adiposity. Case Reports in Dermatological Medicine, 2016, Article ID: 6052194.

[18] Ferraro, G.A., De Francesco, F., Cataldo, C., Rossano, F., Nicoletti, G. and D’Andrea, F. (2012) Synergistic Effects of Cryolipolysis and Shock Waves for Noninvasive Body Contouring. Aesthetic Plastic Surgery, 36, 666-679. https://doi.org/10.1007/s00266-011-9832-7

[19] Riopelle, J.T. and Kovach, B. (2009) Lipid and Liver Function Effects of the Cryolipolysis Procedure in a Study of Male Love Handle Reduction. Lasers in Surgery and Medicine, 82.

[20] Sajjadi, A.Y., Manstein, D. and Carp, S.A. (2017) Measuring Temperature Induced Phase Change Kinetics in Subcutaneous Adipose Tissues Using near Infrared Spectroscopy, MR Imaging and Spectroscopy and OCT. Scientific Reports, 7, Article No. 17786.

[21] Shek, S., Chan, N. and Chan, H. (2012) Non-Invasive Cryolipolysis for Body Contouring in Chinese-A First Commercial Experience. Lasers in Surgery and Medicine, 44, 125-130. https://doi.org/10.1002/1sm.21145

[22] Sun, Z., Yang, Y. and Liu, J. (2013) Alternative Cooling and Heating as a Novel Minimally Invasive Approach for Treating Obesity. International Journal of Thermal Sciences, 64, 29-39. https://doi.org/10.1016/j.ijthermalsci.2012.08.003 